\title{
Vorwort zur neunten Auflage
}

Es ist mir eine große Freude, meine Habilitationsschrift über „Täterschaft und Tatherrschaft" nach mehr als 50 Jahren seit ihrem Erscheinen in neunter Auflage vorlegen zu können. Das Buch, das mich durch mein ganzes Professorenleben begleitet hat, ist in seinem Hauptteil (S. 1-545), wie immer, unverändert. Der „Schlussteil 2015“ (S. 546-800), der die Rechtsentwicklung im Bereich der Täterlehre seit 1963 darstellt, analysiert und auch meine eigenen Auffassungen weiterentwickelt, ist für die Neuauflage gründlich überarbeitet worden.

Ich habe die Rechtsprechung und Literatur der vergangenen zehn Jahre kritisch gewürdigt. Dabei haben die Abschnitte über die „Willensherrschaft kraft organisatorischer Machtapparate“ und über die „Pflichtdelikte“ eine besondere Erweiterung und Vertiefung erfahren. Es handelt sich in beiden Fällen um von mir entwickelte Rechtskonstruktionen, die in der Diskussion um die Täterlehre eine zunehmende Bedeutung gewonnen haben. Die Organisationsherrschaft als Erscheinungsform mittelbarer Täterschaft ist nicht nur vom Bundesgerichtshof übernommen worden, sondern hat auch die Rechtsprechung anderer Länder und des internationalen Strafgerichtshofs erheblich beeinflusst. Auch der Gedanke, dass eine besondere soziale Pflichtenstellung die Täterschaft begründen könne, findet zunehmende Beachtung. Ich hoffe daher, dass auch die Neuauflage meines Buches zur Weiterentwicklung der Täterlehre beitragen kann.

Am Ende meines Vorworts steht der Dank. Ich danke sehr herzlich Frau Marlies Kotting, die nicht nur den Text abgeschrieben und in eine druckreife Form gebracht, sondern auch das Entscheidungsregister angefertigt hat. Ich danke Frau Karin Hergl vom Verlag de Gruyter, die mich nicht nur zu der Neuauflage ermutigt, sondern diese auch in äußerst kooperativer Weise gefördert hat. Ein ganz besonderer Dank gebührt auch meiner lieben Frau. Sie hat nicht nur, wie schon bei der Erstauflage, sämtliche Korrekturen mitgelesen. Sie hat auch die Umstellung des Schlussteils auf Randnummern und das neue Sachverzeichnis in mühsamer Arbeit im Detail überprüft. Ihr sei diese Auflage in herzlicher Verbundenheit gewidmet. 